\title{
Temperature-responsive self-assembly of star block copolymers with poly(ionic liquid) segments
}

\author{
Hideharu Mori, Yuki Ebina, Riina Kambara and Kazuhiro Nakabayashi \\ Novel star block copolymers containing poly( $N$-vinylimidazolium salt) as a poly(ionic liquid) segment and \\ poly( $\mathrm{N}$-isopropylacrylamide) (poly(NIPAAm)) as a thermoresponsive segment were synthesized by reversible addition- \\ fragmentation chain transfer (RAFT) polymerization. Two R-designed tetrafunctional chain transfer agents (CTAs), including \\ a xanthate-type CTA and a dithiocarbamate-type CTA, were compared for the polymerization of 1-ethyl-3-vinylimidazolium \\ bromide (VEI-Br), which is an ionic liquid-type monomer. The dithiocarbamate-type tetrafunctional CTA was the most efficient \\ CTA for the controlled synthesis of four-armed poly(VEI-Br) stars with low polydispersity values and controlled molecular \\ weights. Star block copolymers with inner thermoresponsive segments connected to their core were synthesized by the RAFT \\ polymerization of $\mathrm{VEI}-\mathrm{Br}$, using poly(NIPAAm) stars. In contrast, the RAFT polymerization of NIPAAm using poly(VEI-Br) \\ stars afforded star block copolymers, with block arms consisting of outer block copolymer segments of thermoresponsive \\ poly(NIPAAm). Thermally induced phase separation behavior and assembled structures of star block copolymers were studied \\ in aqueous solution.
}

Polymer Journal (2012) 44, 550-560; doi:10.1038/pj.2012.35; published online 4 April 2012

Keywords: block copolymer; micelle; poly(ionic liquid); self-assembly; star polymer; star block copolymer; thermoresponsive polymer

\section{INTRODUCTION}

Recently, considerable attention has been paid to polymerized ionic liquids or polymeric ionic liquids, which are macromolecules obtained from the polymerization of ionic liquid monomers. ${ }^{1-3}$ Polymeric ionic liquids with unique and attractive properties can be obtained by adjusting the structure of the cation (for example, imidazolium, pyridinium and tetraalkylammonium) and the anion (for example, halide, tetrafluoroborate and hexafluorophosphate). Potential applications of polymeric ionic liquids include polymeric electrolytes, catalytic membranes, ionic conductive materials, $\mathrm{CO}_{2}$ absorbents, microwave absorbents and porous materials. Imidazolium salt is the most popular cation introduced into polymer backbones. A variety of polymers containing imidazolium moieties on their side chains have been developed, including poly(meth)acrylate, ${ }^{4-7}$ polystyrene ${ }^{8,9}$ and poly $(N \text {-vinyl imidazolium })^{10-13}$ derivatives. The majority of these poly(ionic liquid)s were prepared by conventional radical polymerization. In addition to the structure of the substituent on the imidazolium ring, the solubility and properties of poly $(\mathrm{N}$ vinylimidazolium salt) depend on the structure of the counteranion.

As a result of recent progress in controlled radical polymerization (also known as controlled or living radical polymerization or reversible deactivation radical polymerization), well-defined block copolymers containing imidazolium moieties have been synthesized. $^{14,15}$ For example, Waymouth et al. ${ }^{16,17}$ demonstrated the synthesis of a series of block copolymers containing polystyrene and imidazolium-functionalized polystyrene by nitroxide-mediated polymerization, followed by post-synthetic modification of the chloromethyl groups. Recently, Gnanou et al..$^{18}$ reported the synthesis of double hydrophilic block copolymers with ionic responsive properties by the reversible addition-fragmentation chain transfer (RAFT) polymerization of methacrylate-type ionic liquids. RAFT polymerization was also employed for the synthesis of block copolymers containing imidazolium and thiazole groups, which showed characteristic magnetic properties. ${ }^{19}$ In a previous study, we reported the controlled synthesis of poly(ionic liquid) and thermoresponsive-ionic liquid block copolymers by the RAFT polymerization of $\mathrm{N}$-vinylimidazolium salts using a xanthate-type chain transfer agent (CTA). ${ }^{20}$ The RAFT synthesis of double hydrophilic diblock copolymers containing a poly $(N$-vinylimidazolium salt $)$ segment has also been achieved. ${ }^{21}$

The design and synthesis of novel star copolymers with characteristic architectures such as star block copolymers and heteroarm, or miktoarm (mixed) star polymers have attracted significant attention because of their interesting structures and properties. ${ }^{22-28}$ Amphiphilic star block copolymers can form a variety of superstructures via self-organization, and the resulting assembled structures depend on the branched architecture, chemical nature of individual components, composition and molecular weight. Stimuli-responsive 
star polymers such as temperature- and $\mathrm{pH}$-sensitive stars have also attracted significant interest because of their characteristic stimuli-responsive properties, which originate from their branched architecture. In particular, interest in the design and synthesis of star block copolymers with stimuli-responsive segments has increased because the chain architecture (topology) of block copolymers affects their self-assembling behavior and stimuli-responsive properties. ${ }^{29-35}$

Herein, we report the controlled synthesis of novel star block copolymers with poly $(N$-vinylimidazolium salt) as a poly(ionic liquid) segment and poly(NIPAAm) as a thermoresponsive segment by RAFT polymerization. In addition to the comonomer composition and chain length of each segment, the branched structure and location of the thermoresponsive segment affected the stimuliresponsive properties and assembled structure of the material. The RAFT polymerization of 1-ethyl-3-vinylimidazolium bromide (VEI-Br) using tetrafunctional chain transfer agents (CTAs) afforded water-soluble poly(ionic liquid) stars. Poly(NIPAAm) possesses characteristic lower critical solution temperature (LCST)-type thermoresponsive properties and exhibits a soluble-insoluble transition at $32{ }^{\circ} \mathrm{C}$ in water. Thermoresponsive-ionic star block copolymers show characteristic stimuli-responsive behavior owing to their ability to respond to external stimuli such as salt content and temperature, offering additional control over their hierarchical structure, which is formed by self-assembly.

In RAFT polymerization, two different approaches can be used for the synthesis of star polymers, including the R-group approach (propagation from the core) and the Z-group approach (propagation away from the core $).{ }^{36-41}$ Previously, we synthesized poly $(\mathrm{N}$ vinylcarbazole) stars and star block copolymers using the R-group approach in which the leaving groups are linked to the core, and the core is transformed into a radical by fragmentation. ${ }^{42}$ In the present study, two R-designed tetrafunctional CTAs, including a xanthatetype tetrafunctional CTA (CTA 1) and a dithiocarbamate-type tetrafunctional CTA (CTA 2), were used for the synthesis of thermoresponsive-ionic star block copolymers, as shown in Scheme 1. First, we compared the RAFT polymerization of VEI-Br using two R-designed tetrafunctional CTAs for the controlled synthesis of ionic liquid-type star polymers (Scheme 1). Next, we synthesized thermoresponsive-ionic star block copolymers by RAFT polymerization using tetrafunctional macro-CTAs (Scheme 2). Finally, we studied thermally induced phase separation behavior and assembled structures of star block copolymers in aqueous solution.

\section{EXPERIMENTAL PROCEDURE}

\section{Materials}

2,2'-azobis(isobutyronitrile) (AIBN, Kanto Chemical, Tokyo, Japan, 97\%) was purified by recrystallization from methanol. $N$-isopropylacrylamide (NIPAAm, Tokyo Kasei Kogyo, Tokyo, Japan, 98\%) was purified twice by recrystallization from $n$-hexane. All other materials were used without further purification. 1-ethyl-3-vinylimidazolium bromide (VEI-Br) was synthesized by reacting 1-vinylimidazole with bromoethane, according to a slightly modified literature procedure. $^{11}$

CTA 1 was synthesized according to a previously reported two-step procedure. ${ }^{37,42}$ The first step of the procedure involved the reaction of pentaerythritol with 2-bromopropylbromide in the presence of pyridine to yield a tetrafunctional bromide precursor, which was reacted with potassium ethyl xanthogenate to afford the tetrafunctional CTA. CTA 1 was purified by column chromatography on silica gel, using hexane/ethyl acetate $(7 / 3 \mathrm{vol} \%)$ as the eluent to yield a pale yellow viscous oil.

The CTA 2 was synthesized according to a two-step procedure that was similar to the previously reported method for the synthesis of monofunctional

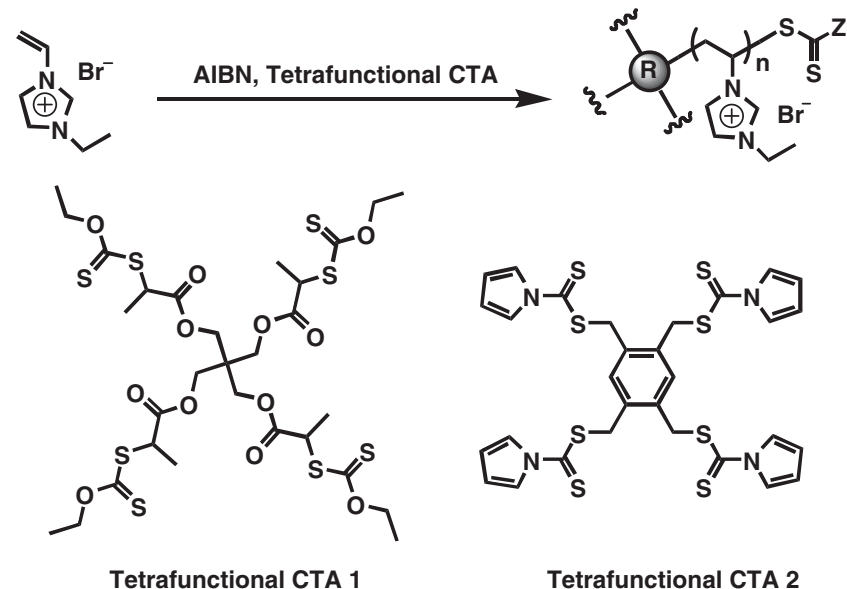

Scheme 1 Synthesis of poly $(N$-vinylimidazolium salt) stars by the reversible addition-fragmentation chain transfer (RAFT) polymerization of 1-ethyl-3vinylimidazolium bromide (VEI-Br) using tetrafunctional chain transfer agents (CTAs).

dithiocarbamate-type CTAs. ${ }^{37}$ Namely, pyrrole $(1.5 \mathrm{~g}, 22.4 \mathrm{mmol})$ was added dropwise to a stirred suspension of sodium hydride $(0.63 \mathrm{~g}$, $26.4 \mathrm{mmol})$ in dimethyl sulfoxide $(20 \mathrm{ml})$. Subsequently, the resulting brown solution was stirred at room temperature for $30 \mathrm{~min}$, and carbon disulfide $(1.74 \mathrm{~g}, 22.9 \mathrm{mmol})$ was added. The solution was allowed to stir at room temperature for $45 \mathrm{~min}$, and 1,2,4,5-tetrakis(bromomethyl)benzene ( $0.45 \mathrm{~g}$, $1.0 \mathrm{mmol}$ ) dissolved in dimethyl sulfoxide $(10 \mathrm{ml})$ was added. After the reaction mixture was stirred at room temperature for $15 \mathrm{~h}$, water and diethyl ether were added. The solid product was washed with water and was isolated by filtration. The crude product was dissolved in a small amount of THF and was purified by precipitation into excess diethylether/ethyl acetate (7/3 vol \%). Finally, the resulting product was isolated by filtration and was dried under vacuum at room temperature to yield CTA 2 as a pale yellow solid $(0.38 \mathrm{~g}$, $55 \%)$. Proton nuclear magnetic resonance $\left({ }^{1} \mathrm{H} \mathrm{NMR}\right)\left(\mathrm{CDCl}_{3}\right): \delta 7.7(\mathrm{t}, 8 \mathrm{H}$, -N-CH-CH- in pyrrole), 7.6 (s, $2 \mathrm{H}, \mathrm{ArH}), 6.3$ (t, $8 \mathrm{H},-\mathrm{N}-\mathrm{CH}-\mathrm{CH}$ - in pyrrole), 4.7 (s, $8 \mathrm{H},-\mathrm{C}-\mathrm{CH}_{2}$-S-) p.p.m. Carbon-13 nuclear magnetic resonance $\left({ }^{13} \mathrm{C}\right.$ $\left.\mathrm{NMR})\left(\mathrm{CDCl}_{3}\right): \delta 197.9(-\mathrm{S}-\mathrm{C}(=\mathrm{S})-\mathrm{N}-), 134.1(\mathrm{ArC}), 133.7(\mathrm{rC})\right), 120.8$ $(-\mathrm{N}-\mathrm{CH}=\mathrm{CH}-), 114.5$ (-N-CH $=\mathrm{CH}-), 38.6$ (-C-CH$-\mathrm{S}-)$ p.p.m. Anal. calcd. for $\mathrm{C}_{30} \mathrm{H}_{26} \mathrm{~N}_{4} \mathrm{~S}_{8}$ : C, 51.54; H, 3.75; N, 8.01; S, 36.69. Found: C, 51.60; H, 3.92; $\mathrm{N}, 7.85 ; \mathrm{S}, 36.36$.

\section{Synthesis of four-armed poly(VEI-Br) star}

All of the polymerizations were carried out using AIBN as an initiator in a degassed sealed tube. The following method is a representative example of the procedure used to synthesize four-armed poly(VEI-Br) stars: VEI-Br $(0.371 \mathrm{~g}$, $1.82 \mathrm{mmol})$, tetrafunctional CTA $2(3.20 \mathrm{mg}, 0.0046 \mathrm{mmol})$, AIBN $(1.5 \mathrm{mg}$, $0.0091 \mathrm{mmol})$ and $N, N$-dimethylformamide (DMF)/methanol $(3 / 1 \mathrm{vol} \%$, $1.48 \mathrm{ml}$ ) were placed in a dry glass ampule equipped with a magnetic stir bar, and the solution was degassed by performing three freeze-evacuate-thaw cycles. After the ampule was flame-sealed under vacuum, the solution was stirred at $60{ }^{\circ} \mathrm{C}$ for $20 \mathrm{~h}$. The reaction was stopped by rapidly cooling the solution with liquid nitrogen, and the resulting mixture was precipitated in excess dichloromethane and was isolated by filtration. The product was dried under vacuum at room temperature to yield four-armed poly(VEI-Br) as a pale yellow solid. To determine the conversion of monomer, the ${ }^{1} \mathrm{H}$ NMR spectrum of the polymerization mixture collected immediately after the polymerization was performed in DMSO- $d_{6}$ at room temperature, and the integration of the monomer $\mathrm{C}=\mathrm{C}-\mathrm{H}$ resonance at 5.9 p.p.m. was compared with the sum of the $\mathrm{N}-\mathrm{CH}-\mathrm{N}$ peak intensities of the imidazolium ring in the polymer and monomer, which were observed at 9.2-9.9 p.p.m. According to this method, the conversion was equal to $31 \%$. Additionally, the polymer yield was gravimetrically determined from a sample of dichloromethane-insoluble polymer $(11 \%, 0.041 \mathrm{~g})$. 


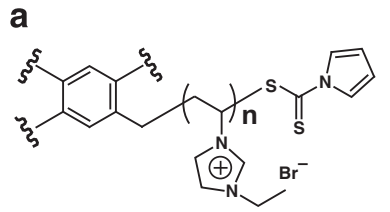

poly(VEI-Br) star

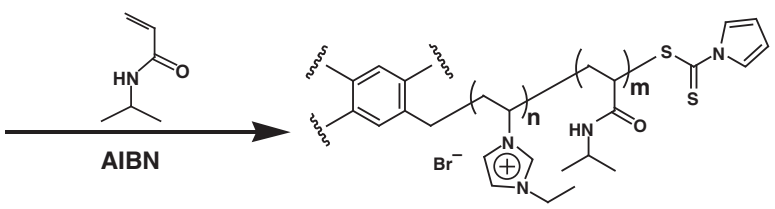

poly(VEI-Br- $b$-NIPAAm) star

b

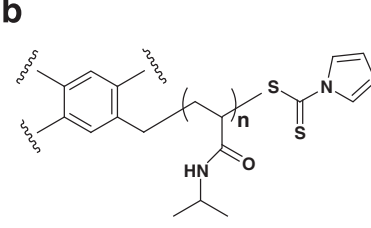

poly(NIPAAm) star
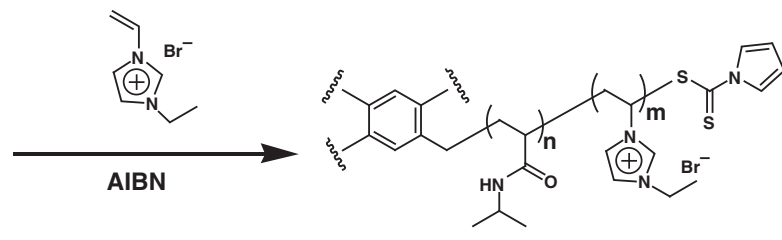

poly(NIPAAm- $b$-VEI-Br) star

Scheme 2 Synthesis of thermoresponsive-ionic star block copolymers through (a) the reversible addition-fragmentation chain transfer (RAFT) polymerization of NIPAAm using poly 1-ethyl-3-vinylimidazolium bromide (VEI-Br) stars as the macro-CTA and (b) the RAFT polymerization of VEI-Br using poly( $N$-isopropylacrylamide) (poly(NIPAAm)) stars as the macro-CTA.

\section{Synthesis of four-armed star block copolymers using poly(VEI-Br) stars}

Dithiocarbamate-terminated poly $(\mathrm{VEI}-\mathrm{Br})$ stars $\left(M_{\mathrm{n}, \mathrm{SEC}}=24900 \mathrm{~g} \mathrm{~mol}^{-1}\right.$, $\left.M_{\mathrm{w}} / M_{\mathrm{n}}=1.07, \quad 0.0274 \mathrm{~g}, \quad 0.0011 \mathrm{mmol}\right), \quad \operatorname{AIBN} \quad(1.5 \mathrm{mg}, \quad 0.0091 \mathrm{mmol})$ NIPAAm $(0.207 \mathrm{~g}, 1.83 \mathrm{mmol})$ and methanol $(2.07 \mathrm{ml})$ were placed in a dry ampule. After the ampule was flame-sealed under vacuum, the solution was stirred at $80^{\circ} \mathrm{C}$ for $6 \mathrm{~h}$. The reaction was stopped by rapidly cooling the solution with liquid nitrogen, and the reaction mixture was precipitated in excess diethyl ether and was isolated by filtration. The resulting product was dried under vacuum at room temperature to yield four-armed star block copolymers $(0.140 \mathrm{~g}$, yield $=60 \%)$, $[\text { poly }(\mathrm{VEI}-\mathrm{Br})-b \text {-poly }(\mathrm{NIPAAm})]_{4}$. The comonomer composition was determined using ${ }^{1} \mathrm{H}$ NMR spectroscopy by comparing the peak at 0.9-1.3 p.p.m., which corresponded to the methyl protons of the NIPAAm unit, and the peak at 9.5-10.6 p.p.m., which was attributed to the imidazolium ring of the VEI-Br unit.

\section{Synthesis of four-armed poly(NIPAAm)}

The following procedure is a representative example of the synthesis of fourarmed poly(NIPAAm) stars: NIPAAm $(0.414 \mathrm{~g}, 3.66 \mathrm{mmol})$, tetrafunctional CTA $(3.20 \mathrm{mg}, 0.0046 \mathrm{mmol})$, AIBN $(1.5 \mathrm{mg}, 0.0091 \mathrm{mmol})$ and methanol $(2.07 \mathrm{ml})$ were placed in a dry glass ampule equipped with a magnetic stir bar, and the solution was degassed by performing three freeze-evacuate-thaw cycles. After the ampule was flame-sealed under vacuum, the solution was stirred at $80^{\circ} \mathrm{C}$ for $1 \mathrm{~h}$. The reaction was stopped by rapidly cooling the solution with liquid nitrogen, and the mixture was precipitated in excess diethyl ether and was isolated by filtration. The resulting product was dried under vacuum at room temperature to yield four-armed poly(NIPAAm) as a white solid $(55 \%, 0.228 \mathrm{~g})$.

\section{Synthesis of four-armed star block copolymer using poly(NIPAAm)} stars

Dithiocarbamate-terminated poly(NIPAAm $)$ stars $\left(M_{\mathrm{n}, \mathrm{SEC}}=19300 \mathrm{~g} \mathrm{~mol}^{-1}\right.$, $\left.M_{\mathrm{w}} / M_{\mathrm{n}}=1.05,0.044 \mathrm{~g}, 0.0046 \mathrm{mmol}\right)$, AIBN $(1.5 \mathrm{mg}, 0.0091 \mathrm{mmol}), \mathrm{VEI}-\mathrm{Br}$ $(0.185 \mathrm{~g}, 0.910 \mathrm{mmol})$ and $\mathrm{DMF} / \mathrm{methanol}(3 / 1 \mathrm{vol} \%, 0.7 \mathrm{ml})$ were placed in a dry ampule. After the ampule was flame-sealed under vacuum, the solution was stirred at $60^{\circ} \mathrm{C}$ for $20 \mathrm{~h}$. The reaction was stopped by rapidly cooling the solution with liquid nitrogen, and the mixture was purified by dialyzing against methanol for 2 days using a Spectra/Por dialysis tube (MWCO: 1000, NIPPON Genetics, Tokyo, Japan). The resulting product was dried under vacuum at room temperature to yield [poly(NIPAAm)- $b$-poly(VEI-Br) $]_{4}$, a four-armed block copolymer $(0.092 \mathrm{~g}$, yield $=40 \%)$.

\section{Instrumentation}

${ }^{1} \mathrm{H}(400 \mathrm{MHz})$ and ${ }^{13} \mathrm{C}$ NMR $(100 \mathrm{MHz})$ spectra were recorded with a JEOL JNM-ECX400 (JOEL, Tokyo, Japan). Fourier transform infrared spectroscopic spectra were obtained with a JASCO FT-IR 210 spectrometer (JASCO, Tokyo, Japan). The number-average molecular weight $\left(M_{n}\right)$ and molecular weight distribution $\left(M_{\mathrm{w}} / M_{\mathrm{n}}\right)$ were estimated by gel permeation chromatography (GPC), using a system consisting of a Tosoh DP-8020 pump (Tosoh, Tokyo, Japan) and a Viscotek TDA model-301 triple detector array (Malvern Instruments, Malvern, UK) (refractive index (RI), Viscosity and RALLS; wavelength $=670 \mathrm{~nm}$ ). Two consecutive columns (Tosoh TSK-GELs (exclusion limited molecular weight, G5000 $\mathrm{PW}_{\mathrm{XL}}-\mathrm{CP} \quad\left(1 \times 10^{6}\right)$, G3000 $\mathrm{PW}_{\mathrm{XL}}-\mathrm{CP}$ $\left(9 \times 10^{4}\right), 30 \mathrm{~cm}$ each) and a guard column (TSK-guard column $\mathrm{PW}_{\mathrm{XL}}-\mathrm{CP}$, $4.0 \mathrm{~cm}$ ) were employed as the column set. The system was operated at a flow rate of $1.0 \mathrm{ml} \mathrm{min}^{-1}$ using acetonitrile/water $(50 / 50 \mathrm{vol} \%)$ containing $0.1 \mathrm{M}$ $\mathrm{NaNO}_{3}$ as the eluent. Poly(ethylene oxide) standards were employed for calibration.

The phase separation temperature of aqueous solutions of the polymers $\left(2.0 \mathrm{mg} \mathrm{ml}^{-1}\right)$ was measured by monitoring the transmittance of a $500-\mathrm{nm}$ beam of light through a quartz sample cell. The transmittance was recorded on a JASCO V-630BIO ultraviolet-visible spectrophotometer equipped with a temperature controller system (JASCO EHC-716 and EHC-717). The temperature was increased at a rate of $1.0^{\circ} \mathrm{Cmin}^{-1}$, and heating scans between 20 and $50{ }^{\circ} \mathrm{C}$ were applied. Characterization of the block copolymers in various solvents was conducted using dynamic light scattering. The measurements were performed using a Sysmex Zetasizer Nano with a He-Ne laser $\left(\lambda_{0}=632.8 \mathrm{~nm}\right)$ at a scattering angle of $90^{\circ}$ (Sysmex, Kobe, Japan). Before the light-scattering measurements, the polymer solutions were filtered into dust-free cylindrical cuvettes using, Millipore Teflon filters with a pore size of $0.2 \mu \mathrm{m}$ (Millipore, Billerica, MA, USA). Height and phase images were obtained via multimode scanning force microscopy. Tapping mode scanning force microscopy observations were performed with an Agilent AFM 5500 (Agilent Technology, Santa Clara, CA, USA), and micro-fabricated cantilevers with a force constant of $\sim 34 \mathrm{~N} \mathrm{~m}^{-1}$ were employed. The samples were prepared by spin-coating the polymers from aqueous solutions heated to $40^{\circ} \mathrm{C}$ onto freshly cleaved mica. In all cases, the images were acquired under ambient conditions at room temperature.

\section{RESULTS AND DISCUSSION}

\section{Synthesis of poly $(N$-vinylimidazolium salt $)$ stars}

For the synthesis of well-defined poly $(N$-vinylimidazolium salt) stars, the selection of a suitable tetrafunctional CTA with effective $\mathrm{R}$ and Z groups is crucial. Recently, we found that xanthate-type CTAs such as $O$-ethyl-S-(1-phenylethyl) dithiocarbonate and O-ethyl-S-(1-ethoxycarbonyl) ethyldithiocarbonate were effective as monofunctional 
CTAs for the controlled homopolymerization of $N$-vinylimidazolium salts. ${ }^{20}$ In our recent investigation, the R-group approach and CTA 1 showed superior performance in the synthesis of well-defined star and star block copolymers by the RAFT polymerization of $\mathrm{N}$-vinylcarbazole. ${ }^{42}$ Similar to $\mathrm{N}$-vinylcarbazole, $\mathrm{N}$-vinylimidazolium salt can be regarded as a non-conjugated $N$-vinyl monomer. In contrast, dithiocarbamate-type CTAs in which the lone pair on the nitrogen atom is part of the aromatic pyrrole ring system, have been employed for the RAFT polymerization of conventional conjugated monomers such as styrene, ${ }^{43,44}$ methyl acrylate ${ }^{44}$ and $\mathrm{N}$-isopropylacrylamide, ${ }^{45}$ and have been used to polymerize less active monomers such as $\mathrm{N}$-vinylphthalimide ${ }^{46}$ and $\mathrm{N}$-vinylnaphthalimide. ${ }^{47}$ On the basis of the aforementioned results, we evaluated two R-designed tetrafunctional CTAs, including a CTA 1 and a CTA 2, as shown in Scheme 1. We initially studied the effectiveness of these tetrafunctional CTAs for the controlled radical polymerization of VEI$\mathrm{Br}$ and the synthesis of well-defined ionic liquid-type star polymers.

The polymerization of VEI-Br using tetrafunctional CTAs was conducted with AIBN in DMF/methanol (3/1 vol \%) at $60^{\circ} \mathrm{C}$ for $20 \mathrm{~h}$ at $[\mathrm{CTA}]_{0} /[\mathrm{AIBN}]_{0}$ ratios ranging from 0.25 to 2.0 and a constant monomer/CTA molar ratio of 400 , and the results are summarized in Table 1. Given the multifunctional nature of the CTAs, which possess four dithioester groups, the CTA-to-AIBN ratio (0.25-2.0) corresponded to the dithioester moiety-to-AIBN ratio of $1-8$. We conducted the polymerizations at a relatively dilute monomer concentration $\left(0.25 \mathrm{~g} \mathrm{ml}^{-1}\right)$. When the polymerization of VEI-Br was conducted with the xanthate-type tetrafunctional CTA (CTA 1) at a $[\mathrm{CTA}]_{0} /[\mathrm{AIBN}]_{0}$ of 0.5 , a poly(VEI-Br) star with a broad polydispersity $\left(M_{\mathrm{w}} / M_{\mathrm{n}}=1.91\right)$ was obtained, and relatively high conversion was observed (63\%, as determined by ${ }^{1} \mathrm{H}$ NMR spectroscopy). The conversion of monomer decreased from $67 \%$ to $16 \%$ as the $[\mathrm{CTA}]_{0} /[\mathrm{AIBN}]_{0}$ ratio increased from 0.25 to 2.0 , and higher $[\mathrm{CTA}]_{0} /$ $[\mathrm{AIBN}]_{0}$ ratios led to the formation of star polymers with narrower molecular weight distributions. In polymerizations with CTA 2, poly $(\mathrm{VEI}-\mathrm{Br})$ stars with lower polydispersities $\left(M_{\mathrm{w}} / M_{\mathrm{n}}=1.19\right)$ were obtained at a $[\mathrm{CTA}]_{0} /[\mathrm{I}]_{0}$ ratio of 0.5 . Polymerization with CTA 2 at higher $[\mathrm{CTA}]_{0} /[\mathrm{I}]_{0}$ ratios $\left([\mathrm{CTA}]_{0} /[\mathrm{I}]_{0}\right.$ ratio $=1$ and 2$)$ resulted in low yields. The aforementioned results are consistent with the general hypothesis that higher CTA/initiator ratios (lower concentration of the initiator) afford better overall control of the polymerization because of a decrease in the number of radicals available for unfavorable side reactions and result in longer polymerization times.

Upon preparing poly(VEI-Br) stars with a wide range of molar masses, different degrees of polymerization were targeted. For this purpose, the polymerization of VEI-Br using two tetrafunctional CTAs was conducted at different $[\mathrm{VEI}-\mathrm{Br}]_{0} /[\mathrm{CTA}]_{0}$ ratios, whereas the CTA/AIBN molar ratio was held constant at $0.5 / 1$ (the dithioester moiety/AIBN molar ratio was set to 2). When the polymerizations were conducted with CTA 2 at a $[\mathrm{VEI}-\mathrm{Br}]_{0} /[\mathrm{CTA}]_{0}$ of $200-800$ in $\mathrm{DMF} /$ methanol $(3 / 1 \mathrm{vol} \%)$ and $60{ }^{\circ} \mathrm{C}$ for $20 \mathrm{~h}$, the conversions were relatively low (31-17\%, as determined by ${ }^{1} \mathrm{H}$ NMR spectroscopy), as shown in Table 2. The number-average molecular weight of the poly(VEI-Br) stars increaseed with an increase in $[\mathrm{M}] /[\mathrm{CTA}]$ ratio, and the molecular weight distribution remained relatively narrow $\left(M_{\mathrm{w}} / M_{\mathrm{n}}=1.11-1.32\right)$, indicating that the molecular weight could be controlled. In all cases, the size-exclusion chromatography (SEC) traces were unimodal, and there was no evidence of high molecular weight species, as shown in Figure 1. In the polymerization with xanthate-type tetrafunctional CTA (CTA 1), higher conversions (53-63\%) were achieved under the same conditions. The star polymer obtained with xanthate-type CTA 1 showed broader polydispersities
Table 1 Synthesis of four-armed poly( $N$-vinyl imidazolium salt) through RAFT polymerization of VEI-Br with tetrafunctional CTAs at different $[\mathrm{CTA}] /[\mathrm{AIBN}]$ ratios in $\mathrm{DMF} / \mathrm{MeOH}(3 / 1 \mathrm{vol} \%)$ at $60^{\circ} \mathrm{C}$ for $20 \mathrm{~h}^{\mathrm{a}}$

\begin{tabular}{lcccccc}
\hline Run & CTA & [CTA]/[AIBN] & $\begin{array}{c}\text { Conv. }^{\mathrm{b}} \\
(\%)\end{array}$ & $\begin{array}{c}M_{n}{ }^{\mathrm{c}} \\
\text { (theory) }\end{array}$ & $\begin{array}{c}M_{n}{ }^{\mathrm{d}} \\
(\mathrm{S} E C)\end{array}$ & $\begin{array}{c}M_{w} M_{n}{ }^{\mathrm{d}} \\
(S E C)\end{array}$ \\
\hline 1 & 1 & 0.25 & 67 & 55200 & 41800 & 2.13 \\
2 & & 0.5 & 63 & 52000 & 46000 & 1.91 \\
3 & & 1 & 36 & 30000 & 40800 & 1.51 \\
4 & & 2 & 16 & 13800 & 39800 & 1.43 \\
\hline 5 & 2 & 0.25 & 57 & 47000 & 33900 & 1.51 \\
6 & & 0.5 & 31 & 25900 & 25000 & 1.19 \\
7 & & 1 & $-{ }^{\mathrm{e}}$ & & & \\
8 & 2 & $-{ }^{\mathrm{e}}$ & & & \\
\hline
\end{tabular}

Abbreviations: AIBN, 2,2'-azobis(isobutyronitrile); CTA, chain transfer agent; DMF, $\mathrm{N}, \mathrm{N}$-dimethylformamide; $\mathrm{MeOH}$, methanol; RAFT, reversible addition-fragmentation chain transfer; SEC, size-exclusion chromatography; VEI-Br, 1-ethyl-3-vinylimidazolium bromide. ${ }^{\mathrm{a}}[\mathrm{M}] /[\mathrm{CTA}]=400,[\mathrm{M}]_{0}=0.25 \mathrm{~g} \mathrm{ml}^{-1}$.

${ }^{\mathrm{b}}$ Calculated by proton nuclear magnetic resonance $\left({ }^{1} \mathrm{H}\right.$ NMR)

${ }^{C} M_{\mathrm{n}}$ (theory) $=\mathrm{MW}$ of $\mathrm{M} \times[\mathrm{M}] /[\mathrm{CTA}] \times$ Conv. $+\mathrm{MW}$ of CTA.

${ }^{d}$ Measured by SEC using poly(ethylene oxide) standards in $\mathrm{H}_{2} \mathrm{O} /$ acetonitrile $(50 / 50$ vol \% containing $0.1 \mathrm{M} \mathrm{NaNO}$ ).

${ }^{\mathrm{e}}$ Conv $<5 \%$.

Table 2 Effect of [M]/[CTA] molar ratio on RAFT polymerization of VEI-Br with tetrafunctional CTAs and AIBN in DMF/MeOH $\left(3 / 1\right.$ vol \%) at $60{ }^{\circ} \mathrm{C}$ for $20 \mathrm{~h}^{\mathrm{a}}$

\begin{tabular}{lcccccc}
\hline Run & CTA & {$[M] /[C T A]$} & $\begin{array}{c}\text { Conv }^{\mathrm{b}} \\
(\%)\end{array}$ & $\begin{array}{c}M_{n}{ }^{\mathrm{c}} \\
\text { (theory) }\end{array}$ & $\begin{array}{c}M_{n}{ }^{\mathrm{d}} \\
(\text { SEC) }\end{array}$ & $\begin{array}{c}M_{w} / M_{n}{ }^{\mathrm{d}} \\
\text { (SEC) }\end{array}$ \\
\hline 1 & 1 & 100 & 53 & 11600 & 27600 & 1.47 \\
2 & 200 & 56 & 23600 & 35800 & 1.73 \\
3 & 400 & 63 & 52000 & 46000 & 1.91 \\
\hline 4 & 2 & 200 & 20 & 8900 & 22100 & 1.11 \\
5 & & 400 & 31 & 25900 & 25000 & 1.19 \\
6 & & 17 & 28400 & 38800 & 1.32
\end{tabular}

Abbreviations: AIBN, 2,2'-azobis(isobutyronitrile); CTA, chain transfer agent; DMF,

$\mathrm{N}, \mathrm{N}$-dimethylformamide; $\mathrm{MeOH}$, methanol; RAFT, reversible addition-fragmentation chain transfer; SEC, size-exclusion chromatography; $\mathrm{VEI}-\mathrm{Br}$, 1-ethyl-3-vinylimidazolium bromide. a[CTA]/[AIBN] $=0.5,[M]_{0}=0.25 \mathrm{~g} \mathrm{ml}^{-1}$.

${ }^{b}$ Calculated by proton nuclear magnetic resonance $\left({ }^{1} \mathrm{H}\right.$ NMR).

${ }^{\mathrm{C}} M_{\mathrm{n}}$ (theory) $=\mathrm{MW}$ of $\mathrm{M} \times[\mathrm{M}] /[\mathrm{CTA}] \times$ Conv. $+\mathrm{MW}$ of CTA

dMeasured by SEC using poly(ethylene oxide) standards in $\mathrm{H}_{2} \mathrm{O} /$ acetonitrile $(50 / 50 \mathrm{vol} \%$ containing $0.1 \mathrm{M} \mathrm{NaNO}_{3}$ )

$\left(M_{\mathrm{w}} / M_{\mathrm{n}}=1.47-1.91\right)$ compared with those obtained with dithiocarbamate-type CTA 2. This behavior is consistent with the general trend in transfer constants, which decrease according to the following series: pyrrole $\gg$ alkoxy. ${ }^{48}$ In other words, the transfer constant of dithiocarbamate-type CTA 2 was high enough to yield polymers with low polydispersities but resulted in relatively low monomer conversion. Unfortunately, the exact number and molecular weight of the arms of the stars could not be determined because CTA 2 does not possess a cleavable linkage between the core and arm. Nevertheless, the results of our investigation are in good agreement with the theoretical guidelines, suggesting that well-defined star polymers can be obtained from monomers with high propagation rate coefficients when the R-group approach is used. ${ }^{38,41}$ In fact, the R-group approach has been successfully used for the synthesis of welldefined star polymers of vinyl acetate, ${ }^{37,49} \mathrm{~N}$-vinyl pyrrolidone ${ }^{50}$ and $\mathrm{N}$-vinylcarbazole ${ }^{42}$ which form relatively unstable (reactive) 

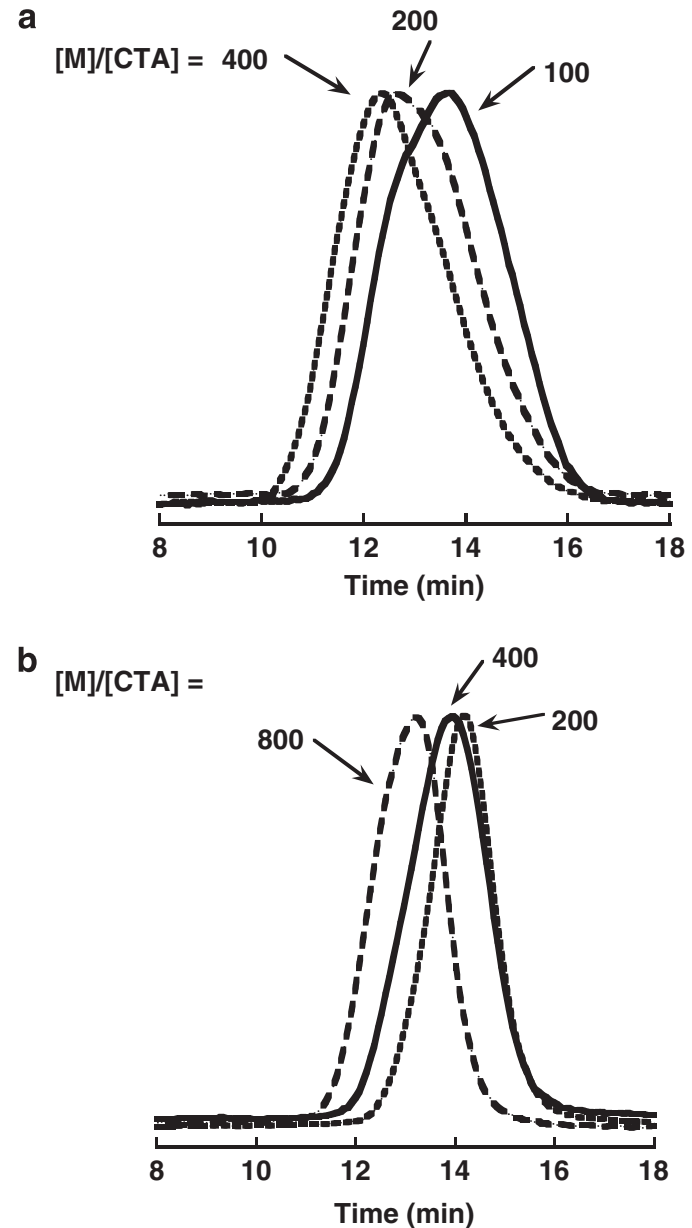

Figure 1 Size-exclusion chromatography (SEC) traces of four-armed poly 1-ethyl-3-vinylimidazolium bromide (VEI-Br) stars obtained with (a) chain transfer agent (CTA) 1 and (b) dithiocarbamate-type tetrafunctional CTA (CTA 2) at different $[\mathrm{VEI}-\mathrm{Br}]_{0} /[\mathrm{CTA}]_{0}$ ratios (see Table 2 for the experimental conditions).

propagating radical species and have relatively large propagation rate coefficients.

Synthesis of star block copolymers

For the synthesis of well-defined thermoresponsive-ionic block copolymers, we selected poly $(N$-vinylimidazolium salt $)$ as an ionic segment and poly(NIPAAm) as a thermoresponsive segment. Dithiocarbamate-type CTA 2 was employed for the synthesis of star block copolymers with low polydispersities and pre-determined comonomer compositions and segment chain lengths. We initially attempted the synthesis of star block copolymers with poly(VEI-Br) and poly(NIPAAm) segments as separated inner and outer blocks through the polymerization of NIPAAm, using poly(VEI-Br) stars as the tetrafunctional macro-CTA, as shown in Scheme 2a. In all cases, the polymerization of NIPAAm was carried out with AIBN, using dithiocarbamate-terminated poly(VEI-Br) stars as the macro-CTA at $80^{\circ} \mathrm{C}$ in methanol. The monomer-to-CTA ratio was varied to control the comonomer content and the molecular weight of the star block copolymer. Under the experimental conditions, the conversions determined by ${ }^{1} \mathrm{H}$ NMR spectroscopy were $71-92 \%$, and the polymers were recovered by precipitation in diethyl ether (Table 3 ). Figure $2 \mathrm{a}$ presents the SEC traces of the starting poly(VEI-Br) star
Table 3 Synthesis of star block copolymers by RAFT polymerization of NIPAAm using AIBN and poly(VEI-Br) star as macro-CTA in $\mathrm{MeOH}$ at $80^{\circ} \mathrm{C}$ for $6 \mathrm{~h}^{\mathrm{a}}$

\begin{tabular}{lcccccc}
\hline Run & [M]/[CTA]/[I] & $\begin{array}{c}\text { Conv. }^{\mathrm{b}} \\
\text { (\%) }\end{array}$ & $\begin{array}{c}M_{n}{ }^{\mathrm{c}} \\
\text { (theory) }\end{array}$ & $\begin{array}{c}M_{n}{ }^{\mathrm{d}} \\
\text { (SEC) }\end{array}$ & $\begin{array}{c}M_{w} / M_{n}{ }^{\mathrm{d}} \\
\text { (SEC) }\end{array}$ & $\begin{array}{c}\text { Composition }^{\mathrm{b}} \\
\text { VEI-Br: NIPAAm }\end{array}$ \\
\hline 1 & $200 / 0.125 / 1$ & 92 & 191200 & 28700 & 1.17 & $5: 95$ \\
2 & $50 / 0.25 / 1$ & 82 & 43400 & 27900 & 1.22 & $64: 36$ \\
3 & $100 / 0.25 / 1$ & 76 & 59300 & 26700 & 1.18 & $38: 62$ \\
4 & $200 / 0.25 / 1$ & 71 & 89100 & 26000 & 1.11 & $18: 82$ \\
\hline
\end{tabular}

Abbreviations: AIBN, 2,2'-azobis(isobutyronitrile); CTA, chain transfer agent; $\mathrm{MeOH}$, methanol; NIPAAm, $N$-isopropylacrylamide; RAFT, reversible addition-fragmentation chain transfer; SEC, size-exclusion chromatography; VEI-Br, 1-ethyl-3-vinylimidazolium bromide.

${ }^{a}[\mathrm{M}]_{0}=0.10 \mathrm{~g} \mathrm{ml}^{-1}(\mathrm{MeOH})$, macro-CTA $=$ poly(VEI-Br) star $\left[M_{\mathrm{n}}=24900, M_{\mathrm{w}} / M_{\mathrm{n}}=1.07\right]$ ${ }^{\mathrm{b}}$ Calculated by proton nuclear magnetic resonance ( ${ }^{1} \mathrm{H}$ NMR).

${ }^{\mathrm{C}} M_{\mathrm{n}}$ (theory) $=\mathrm{MW}$ of $\mathrm{M} \times[\mathrm{M}] /[$ macro-CTA $] \times$ Conv. $+\mathrm{MW}$ of macro-CTA.

Measured by SEC using poly(ethylene oxide) standards in $\mathrm{H}_{2} \mathrm{O}$ /acetonitrile ( $50 / 50$ vol\% containing $0.1 \mathrm{~m} \mathrm{NaNO} 3$ ).
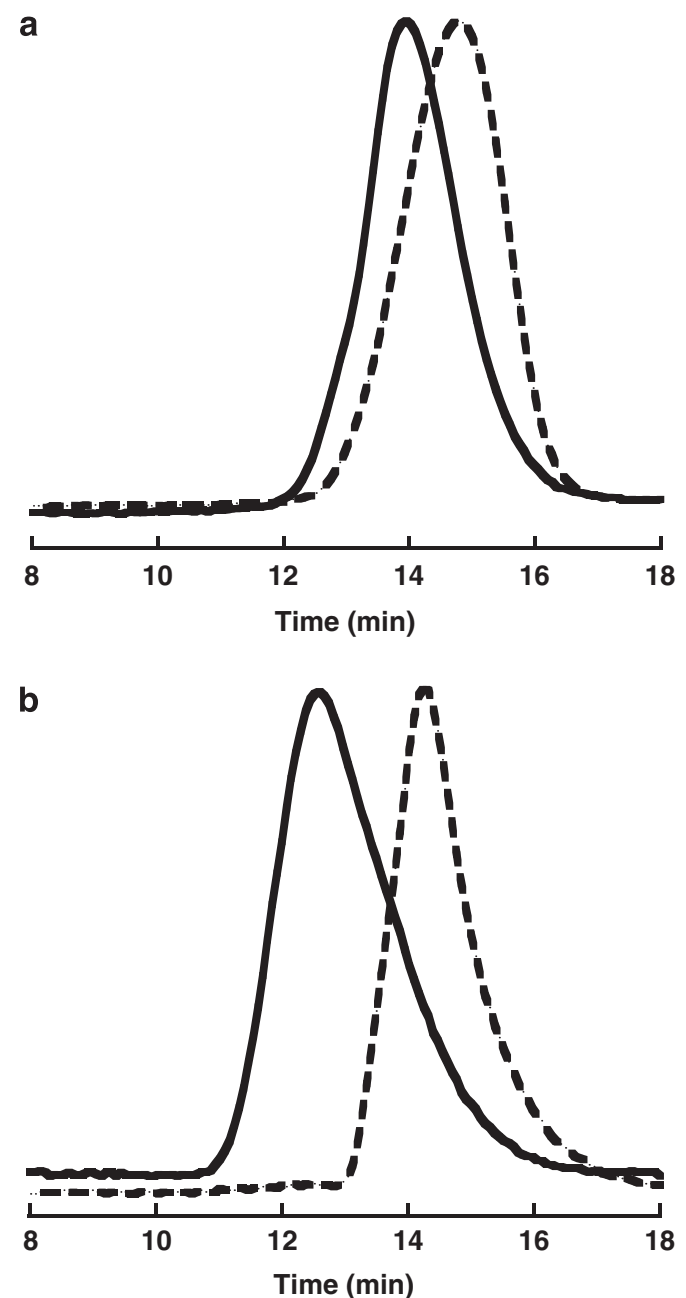

Figure 2 Size-exclusion chromatography (SEC) traces of star block copolymers and macro-chain transfer agents (CTAs): (a) [poly 1-ethyl-3vinylimidazolium bromide (VEI-Br)-b-poly(NIPAAm) $]_{4}$ (solid line, $M_{\mathrm{n}}=$ 28700, $M_{\mathrm{w}} / M_{\mathrm{n}}=1.17$ ) and poly(VEI-Br) star (dotted line, $M_{\mathrm{n}}=24900$, $\left.M_{\mathrm{w}} / M_{\mathrm{n}}=1.07\right)$ and (b) [poly(NIPAAm)- $b$-poly(VEI-Br) $]_{4}$ (solid line, $M_{\mathrm{n}}=39100$, $\left.M_{\mathrm{w}} / M_{\mathrm{n}}=1.57\right)$ and poly $(N$-isopropylacrylamide) (poly(NIPAAm)) star (dotted line, $\left.M_{\mathrm{n}}=19300, M_{\mathrm{w}} / M_{\mathrm{n}}=1.05\right)$. 
macro-CTA and second growth polymer, which was obtained by the polymerization of NIPAAm. A shift in the SEC trace toward a higher molecular weight regions was observed, and the degree of polydispersity remained constant at $M_{\mathrm{w}} / M_{\mathrm{n}}<1.22$, which indicates efficient block formation. In the ${ }^{1} \mathrm{H}$ NMR spectrum of the star block copolymer measured in $\mathrm{D}_{2} \mathrm{O}$ at $25^{\circ} \mathrm{C}$, the peaks corresponding to both components are clearly detected (Figure $3 \mathrm{a}$ ). The comonomer composition and molecular weight of the resulting block copolymers could be adjusted by changing the $[\mathrm{M}] /[$ macro-CTA $]$ ratio of the feed. These results suggest that fragmentation from the intermediate radical to the poly(VEI-Br) radical combined with reinitiation is efficient, and the rapid conversion of poly(VEI-Br) macro-CTA into block copolymers occurs under the experimental conditions.

In the next stage, we conducted the polymerization of VEI-Br using the dithiocarbamate-terminated poly(NIPAAm) star as the macroCTA under suitable conditions. The chain extension of the fourarmed poly(NIPAAm) star of VEI-Br results in the formation of a star block copolymer in which poly(NIPAAm) is linked to the core and exists as an inner block segment, and poly(VEI-Br) exists as an outer block segment, as shown in Scheme $2 \mathrm{~b}$. The polymerization of PVI-Br in the presence of the dithiocarbamate-terminated poly(NIPAAm) star was conducted in DMF/methanol (3/1 vol \%) at $60{ }^{\circ} \mathrm{C}$ for $20 \mathrm{~h}$ (Table 4). Figure $2 \mathrm{~b}$ shows the SEC traces of the parent poly(NIPAAm) star and resulting star block copolymer. Although the molecular weight distribution of the resulting star block copolymer is relatively broad, a shift in the SEC trace toward higher molecular ranges is observed. These results suggest that the polymerization of the $N$-vinylimidazolium salt mediated by the dithiocarbonate- functionalized poly(NIPAAm) star shows reasonable control under the experimental conditions, resulting in the formation of star block copolymers.

\section{Thermal phase transition and assembled structure in aqueous} solution

In this study, poly( $N$-vinylimidazolium salt) was selected as an ionic segment and poly(NIPAAm) was employed as a thermoresponsive segment. Poly(NIPAAm) possesses characteristic LCST-type thermoresponsive properties and exhibits a solubleinsoluble transition at $32^{\circ} \mathrm{C}$ in water. Although both

Table 4 Synthesis of star block copolymers by RAFT polymerization of VEI-Br using AIBN and poly( $N$-isopropylacrylamide) (poly(NIPAAm)) star as macro-CTA in DMF/MeOH (3/1 vol \%) at $60{ }^{\circ} \mathrm{C}$ for $20 \mathrm{~h}$

\begin{tabular}{lcccccc}
\hline Run & $\begin{array}{c}{[M] /} \\
{[C T A] /[1]}\end{array}$ & $\begin{array}{c}\text { Conv. }^{\mathrm{a}} \\
(\%)\end{array}$ & $\begin{array}{c}M_{n}{ }^{\mathrm{b}} \\
(\text { theory })\end{array}$ & $\begin{array}{c}M_{n}{ }^{\mathrm{c}} \\
(\text { SEC) }\end{array}$ & $\begin{array}{c}M_{w} / M_{n}{ }^{\mathrm{c}} \\
(\text { SEC) }\end{array}$ & $\begin{array}{c}\text { Composition }^{\mathrm{a}} \\
\text { NIPAAm }: \text { VEI-Br }\end{array}$ \\
\hline $1^{\mathrm{d}}$ & $100 / 0.25 / 1$ & 85 & 88300 & 39100 & 1.57 & $13: 87$ \\
$2^{\mathrm{e}}$ & $100 / 0.125 / 1$ & 81 & 156200 & 41900 & 1.49 & $38: 62$ \\
\hline
\end{tabular}

Abbreviations: AIBN, 2,2'-azobis(isobutyronitrile); CTA, chain transfer agent; $\mathrm{MeOH}$, methanol; NIPAAm, $N$-isopropylacrylamide; RAFT, reversible addition-fragmentation chain transfer; SEC, size-exclusion chromatography; VEI-Br, 1-ethyl-3-vinylimidazolium bromide. ${ }^{a}$ Calculated by proton nuclear magnetic resonance ( ${ }^{1} \mathrm{H}$ NMR).

${ }^{\mathrm{b}} \mathrm{M}_{\mathrm{n}}$ (theory) $=\mathrm{MW}$ of $\mathrm{M} \times[\mathrm{M}] /[$ macro-CTA $] \times$ Conv. $+\mathrm{MW}$ of macro-CTA

'Measured by SEC using poly(ethylene oxide) standards in $\mathrm{H}_{2} \mathrm{O} /$ acetonitrile $(50 / 50 \mathrm{vol} \%$ containing $0.1 \mathrm{M} \mathrm{NaNO}$ ).

$\mathrm{d}[\mathrm{M}]_{0}=0.25 \mathrm{~g} \mathrm{ml}^{-1}$, macro-CTA $=$ poly (NIPAAm) $\operatorname{star}\left[M_{\mathrm{n}}=19300, M_{w} / M_{\mathrm{n}}=1.05\right]$

$\mathrm{e}[\mathrm{M}]_{0}=0.10 \mathrm{~g} \mathrm{ml}^{-1}$, macro-CTA $=$ poly(NIPAAm) star $\left[M_{\mathrm{n}}=24700, M_{\mathrm{w}} / M_{\mathrm{n}}=1.03\right]$. a

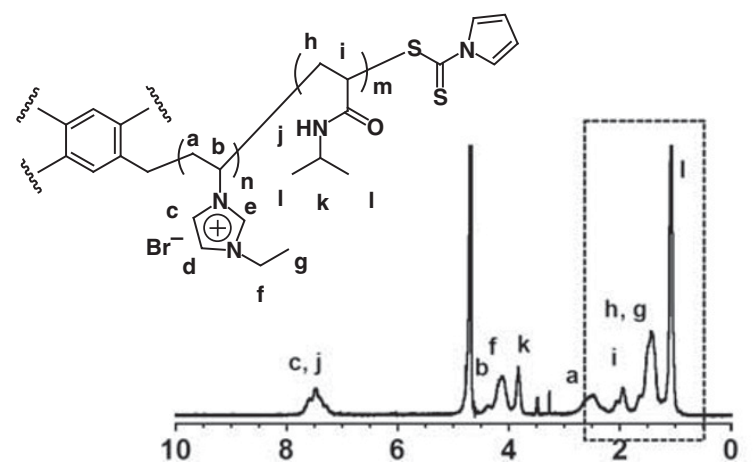

b

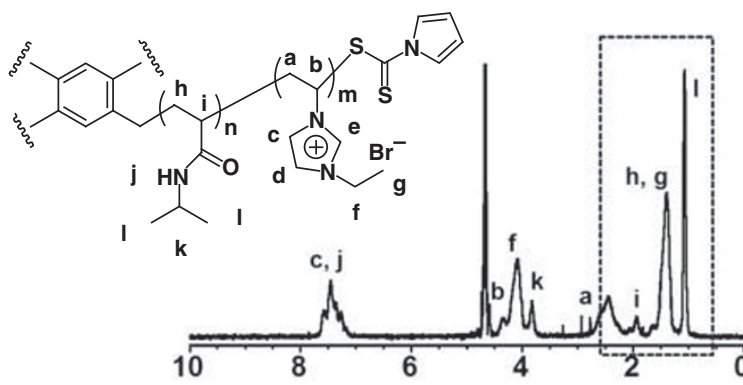

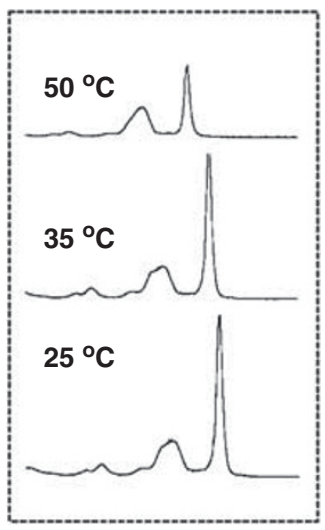

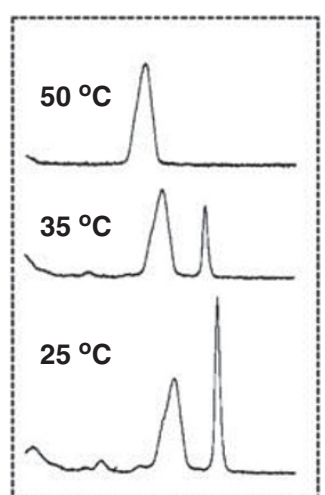

Figure 3 Proton nuclear magnetic resonance $\left({ }^{1} \mathrm{H}\right.$ NMR) spectra $\left(\mathrm{D}_{2} \mathrm{O}\right)$ of star block copolymers at various temperatures: (a) [poly 1-ethyl-3-vinylimidazolium bromide $\left.(\mathrm{VEI}-\mathrm{Br})_{62}\right]_{4}-b$-poly(NIPAAm) $\left.)_{36}\right]_{4}$ obtained by the polymerization of NIPAAm using poly $(\mathrm{VEI}-\mathrm{Br})$ star and $(\mathrm{b})$ [poly $(\mathrm{NIPAAm})_{38}-b$-poly $\left.(\mathrm{VEI}-\mathrm{Br})_{62}\right]_{4}$ obtained by the polymerization of $\mathrm{VEI}-\mathrm{Br}$ using poly(N-isopropylacrylamide) (poly(NIPAAm)) star. 

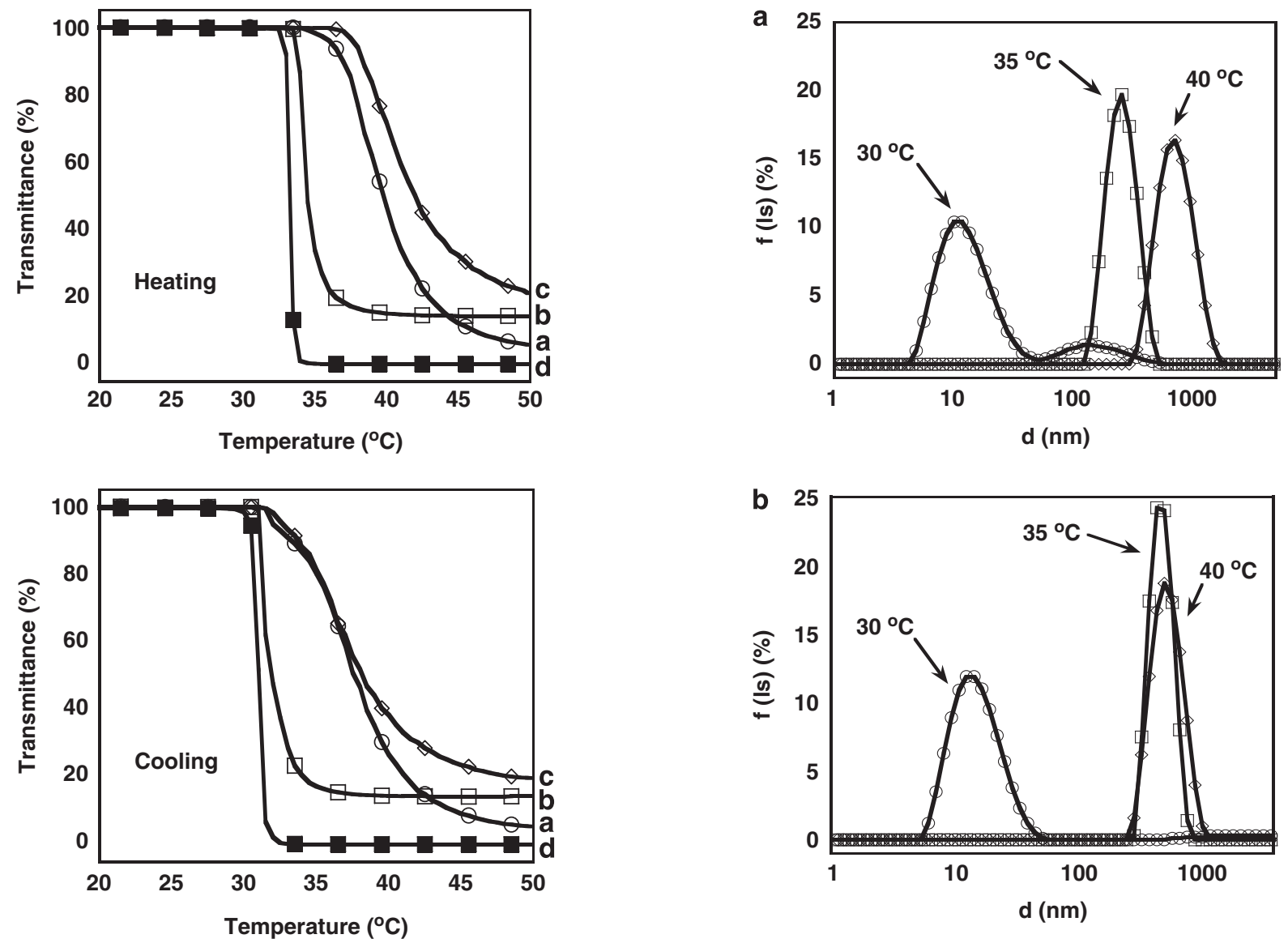

Figure 4 Temperature dependence of the transmittance at $500 \mathrm{~nm}$ in aqueous solutions (polymer conc. $=2.0 \mathrm{mg} \mathrm{ml}^{-1}$ ) of (a) [poly 1-ethyl-3vinylimidazolium bromide $(\mathrm{VEI}-\mathrm{Br})_{64}-b$-poly(NIPAAm) $\left.{ }_{36}\right]_{4}$, (b) [poly(NIPAAm) $38^{-}$ $b$-poly(VEI-Br) $\left.{ }_{62}\right]_{4}$, (c) poly(VEI-Br) $)_{47}-b$-poly(NIPAAm) 53 and (d) four-armed poly(N-isopropylacrylamide) (poly(NIPAAm)) stars. Upper and lower figures represent heating and cooling cycles, respectively.

poly(N-vinylimidazolium salt) and poly(NIPAAm) segments are soluble in water at room temperature, the star block copolymer may associate into micelle-like aggregations with a dehydrated poly(NIPAAm) core and a hydrophilic poly $(N$-vinylimidazolium salt) shell at temperatures greater than the LCST of the poly(NIPAAm) segment.

The temperature-induced formation of assembled structures of star block copolymers was initially evaluated by assessing ${ }^{1} \mathrm{H}$ NMR spectra measured in $\mathrm{D}_{2} \mathrm{O}$, as shown in Figure 3. In the star block copolymer with block arms consisting of inner block copolymer segments of thermoresponsive poly(NIPAAm) ([poly(NIPAAm)- $b$-poly(VEI-Br) $]_{4}$ ), the spectrum obtained in $\mathrm{D}_{2} \mathrm{O}$ at $25^{\circ} \mathrm{C}$ represents peaks associated with each segment. As shown in Figure $3 \mathrm{~b}$, the peak intensity of the signal at $0.9-1.3$ p.p.m., which corresponds to the methyl protons of the NIPAAm unit, decreases with an increase in temperature. The peak attributed to the NIPAAm unit was almost invisible at $50{ }^{\circ} \mathrm{C}$, probably because of the aggregation of collapsed poly(NIPAAm) chains. In contrast, although the peak attributed to the NIPAAm unit of the star block copolymer with block arms consisting of outer block copolymer segments of thermoresponsive poly(NIPAAm) ([poly(VEI$\mathrm{Br})$ - $b$-poly(NIPAAm) $]_{4}$ ) decreases with an increase in temperature, the peak is visible at $50^{\circ} \mathrm{C}$. These results indicate that micelles

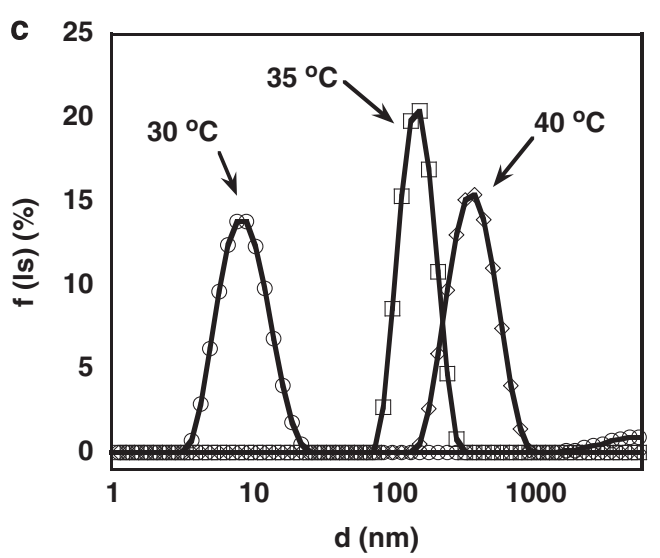

Figure 5 Hydrodynamic diameter distributions $\left(f\left(D_{h}\right)\right)$ of micelles obtained from (a) [poly 1-ethyl-3-vinylimidazolium bromide (VEI-Br) 64 - $b$ poly(NIPAAm) $\left.{ }_{36}\right]_{4}$, (b) [poly(NIPAAm) $)_{38}-b$-poly $\left.(\mathrm{VEI}-\mathrm{Br})_{62}\right]_{4}$ and (c) poly(VEI$\mathrm{Br})_{47}$-b-poly(NIPAAm) 53 .

consisting of a collapsed poly(NIPAAm) core and a hydrophilic shell of poly(VEI-Br) form in $\mathrm{D}_{2} \mathrm{O}$ at $50{ }^{\circ} \mathrm{C}$, and that the location of the thermoresponsive segments in the star block copolymer may have a significant impact on the temperature-induced self-assembly process.

We also evaluated the thermally induced phase separation behavior of the star block copolymers in water by monitoring the solutions by ultraviolet-visible spectroscopy $(500 \mathrm{~nm})$ at a fixed heating rate of $1.0^{\circ} \mathrm{C} \mathrm{min}^{-1}$. The linear block copolymer poly(NIPAAm)- $b$-poly (VEI-Br) and the poly(NIPAAm) star were prepared independently and were evaluated for comparison. As shown in Figure 4, the star 
block copolymer $[\text { poly(NIPAAm)- } b \text {-poly(VEI-Br) }]_{4}$ was soluble in water at low temperatures and underwent a clear phase transition from $34-36{ }^{\circ} \mathrm{C}$ upon heating. Moreover, the solution became turbid at $50{ }^{\circ} \mathrm{C}$ (transparency $\left.=14 \%\right)$. In contrast, a broader phase transition from $100 \%$ at $30^{\circ} \mathrm{C}$ to $<10 \%$ at $50{ }^{\circ} \mathrm{C}$ is detected for the [poly (VEI-Br)-b-poly(NIPAAm) $]_{4}$ star block copolymer, which possesses a

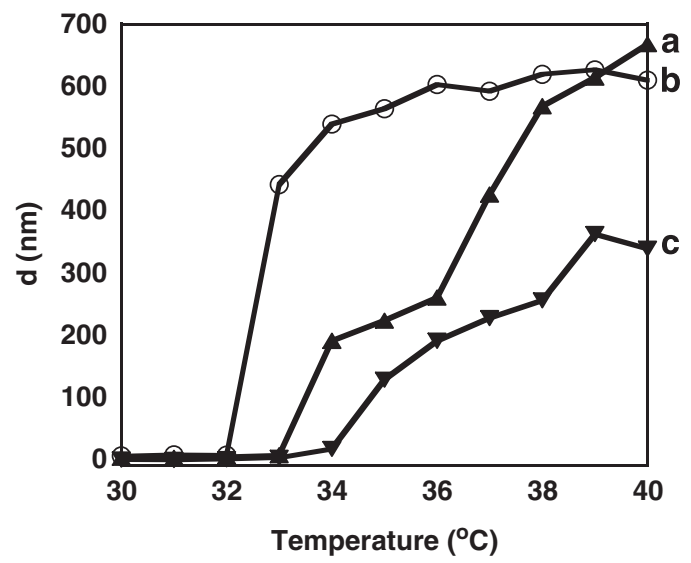

Figure 6 Temperature dependence of the hydrodynamic diameter of micelles obtained from (a) [poly 1-ethyl-3-vinylimidazolium bromide (VEI$\mathrm{Br}_{64}-b$-poly(NIPAAm) $\left.{ }_{36}\right]_{4}, \quad$ (b) [poly(NIPAAm) ${ }_{38}-b$-poly $\left.(\mathrm{VEI}-\mathrm{Br})_{62}\right]_{4}$ and (c) poly(VEI-Br $)_{47}$-b-poly(NIPAAm) $)_{53}$. transition temperature that is slightly higher than that of [poly (NIPAAm)- $b$-poly(VEI-Br) $]_{4}$. In both cases, the transition temperature and thermoresponsive behavior are different from that of poly(NIPAAm) stars, indicating that the introduction of ionic poly(VEI-Br) segments increases the transition temperature, which is consistent with the general hypothesis that the LCST depends on the distribution of hydrophilic and hydrophobic groups within the polymers, and that the transition temperature increases with an increase in the degree of hydrophilicity. In the linear block copolymer, the transmittance decreases gradually from $100 \%$ at $30{ }^{\circ} \mathrm{C}$ to $25 \%$ at $50{ }^{\circ} \mathrm{C}$. In all cases, when the white turbid solution was cooled, the copolymer returned to a homogeneous state. This phase separation was reversible upon heating and cooling, and hysteresis was not observed. These results suggest that the transition temperature and thermoresponsive behavior are affected by the branched structure and location of the thermoresponsive segments.

The solution properties and temperature-induced self-assembling behavior of the star block copolymers were characterized by performing dynamic light scattering in $0.5 \mathrm{gl}^{-1}$ aqueous solutions $\left(1.0 \mathrm{gl}^{-1}\right.$ $\mathrm{NaCl}$ ). As shown in Figure 5b, the star block copolymer [poly (NIPAAm)- $b$-poly(VEI-Br) $]_{4}$ shows a monomodal hydrodynamic diameter distribution $\left(D_{\mathrm{h}}=570 \mathrm{~nm}\right)$ in aqueous solution (conc. $=1.0$ $\mathrm{mg} \mathrm{ml}^{-1}$ ) at $35^{\circ} \mathrm{C}$. The relatively large hydrodynamic diameter indicates that micelles consisting of a relatively hydrophobic core of poly(NIPAAm) and a hydrophilic shell of poly(VEI-Br) aggregated in solution. Upon heating to temperatures $>40{ }^{\circ} \mathrm{C}$, the size and distribution of the aggregates remain constant. As expected, micelle

a
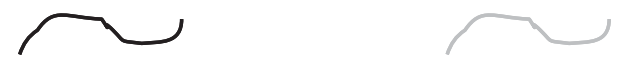

poly(NIPAAm) segment

poly(ionic liquid) segment

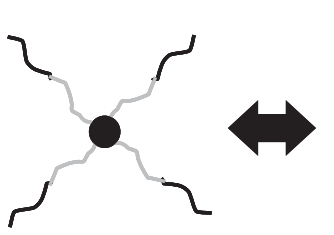

poly(VEI-Br-b-NIPAAm) star
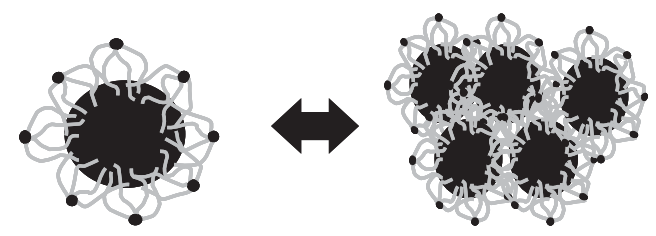

$230 \mathrm{~nm}$

$670 \mathrm{~nm}$

b

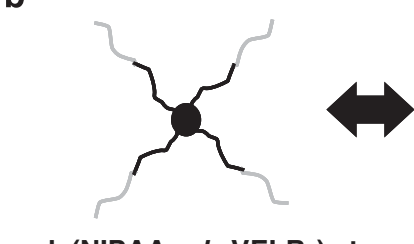

poly(NIPAAm- $b-\mathrm{VEI}-\mathrm{Br}$ ) star
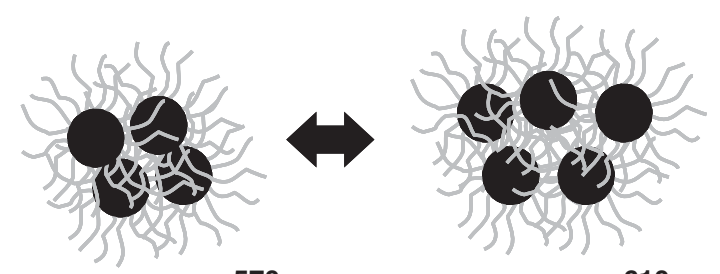

C
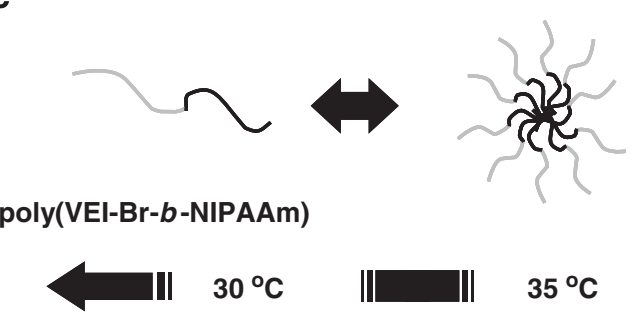

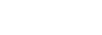

$610 \mathrm{~nm}$

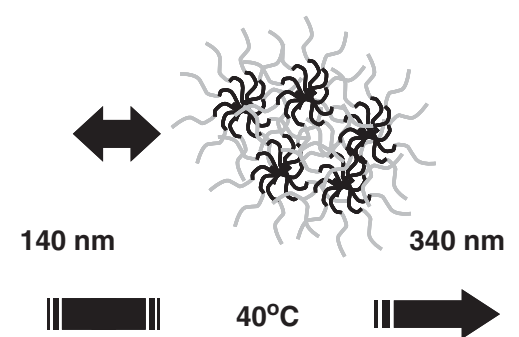

Scheme 3 Proposed mechanism of the temperature-induced self-assembly of thermoresponsive-ionic star block copolymers in aqueous solution: (a) [poly 1-ethyl-3-vinylimidazolium bromide (VEI-Br)-b-poly(NIPAAm) $]_{4}$, (b) [poly(NIPAAm)-b-poly(VEI-Br) $]_{4}$ and (c) poly(VEI-Br)-b-poly(NIPAAm). 
formation was not observed in the block copolymer at $30{ }^{\circ} \mathrm{C}$. In the star block copolymer $[\text { poly(VEI-Br)- } b \text {-poly(NIPAAm) }]_{4}$, a constant increase in the diameter is observed, as the temperature increased (from $D_{\mathrm{h}}=230 \mathrm{~nm}$ at $35^{\circ} \mathrm{C}$ to $670 \mathrm{~nm}$ at $40{ }^{\circ} \mathrm{C}$, Figure $5 \mathrm{a}$ ).

Figure 6 exhibits the temperature dependence of the hydrodynamic diameter of the micelles obtained from star and linear block copolymers. In the star block copolymer [poly(NIPAAm)- $b$-poly $(\mathrm{VEI}-\mathrm{Br})]_{4}$, as the temperature increases, a dramatic increase in the diameter is observed $\left(D_{\mathrm{h}}\right.$ increases from $<17 \mathrm{~nm}$ at $32{ }^{\circ} \mathrm{C}$ to $450 \mathrm{~nm}$ at $33{ }^{\circ} \mathrm{C}$, Figure 6), which corresponds to the LCST-type solubleinsoluble transition of the poly(NIPAAm) chains. A further increase in the solution temperature results in a slight increase in the size of the material $\left(D_{\mathrm{h}}=\sim 610 \mathrm{~nm}\right.$ at $\left.40^{\circ} \mathrm{C}\right)$. In contrast, [poly(VEI-Br)$b$-poly(NIPAAm) $]_{4}$ shows a two-step transition process. Namely, small micelles form at $\sim 33{ }^{\circ} \mathrm{C}$ and further aggregate into dehydrated clusters. The diameter of the linear block copolymer poly(VEI-Br $)_{47^{-}}$ $b$-poly(NIPAAm $)_{53}$ increases slowly with an increase in temperature, and a similar two-step transition process is observed (from $D_{\mathrm{h}}<15 \mathrm{~nm}$ at $33^{\circ} \mathrm{C}$ to $340 \mathrm{~nm}$ at $40^{\circ} \mathrm{C}$ ).

The proposed mechanism of the temperature-induced self-assembly of thermoresponsive-ionic star block copolymers in aqueous solution is shown in Scheme 3. The star block copolymer with inner thermoresponsive segments connected to its core ([poly(NIPAAm)$b$-poly(VEI-Br) $]_{4}$ ) may initially form unimolecular micelles upon heating owing to the collapse of poly(NIPAAm) segments in the core, which can be regarded as an intramolecular aggregation. The resulting unimolecular micelles consist of a dehydrated poly(NIPAAm) core surrounded by poly( $N$-vinylimidazolium salt) segments, which may aggregate rapidly as a result of the association of poly(NIPAAm) clusters and their increased hydrophobicity at higher temperature, as shown in Scheme 3b. A further increase in the solution temperature led to a slight increase in the size of the aggregates. Permanently charged polyelectrolyte shells in the core-shell micelles help to prevent further aggregation by the repulsion forces in the ionic segment, which results in the formation of stable micelles. Hence, poly(ionic liquid) segments in the shell have a lower repulsion force than that of normal polyelectrolytes, which promotes further aggregation.

In $[\text { poly }(\mathrm{VEI}-\mathrm{Br})-b \text {-poly(NIPAAm) }]_{4}$, the star block copolymer with outer thermoresponsive segments, relatively stable micelle-like aggregates consisting of poly(VEI-Br) chains and the original hydrophobic core in the shell are initially formed at temperatures above the LCST of the poly(NIPAAm) segment (Scheme 3a). A further increase in the temperature promoted aggregation into dehydrated clusters. Compared with linear block copolymers at $40^{\circ} \mathrm{C}$, the formation of larger aggregates of star block copolymers may be because of their branched structure in which several arms are attached to a central core. The limited motion of inner segments connected to the central core restricts the temperature-induced selfassembling process.
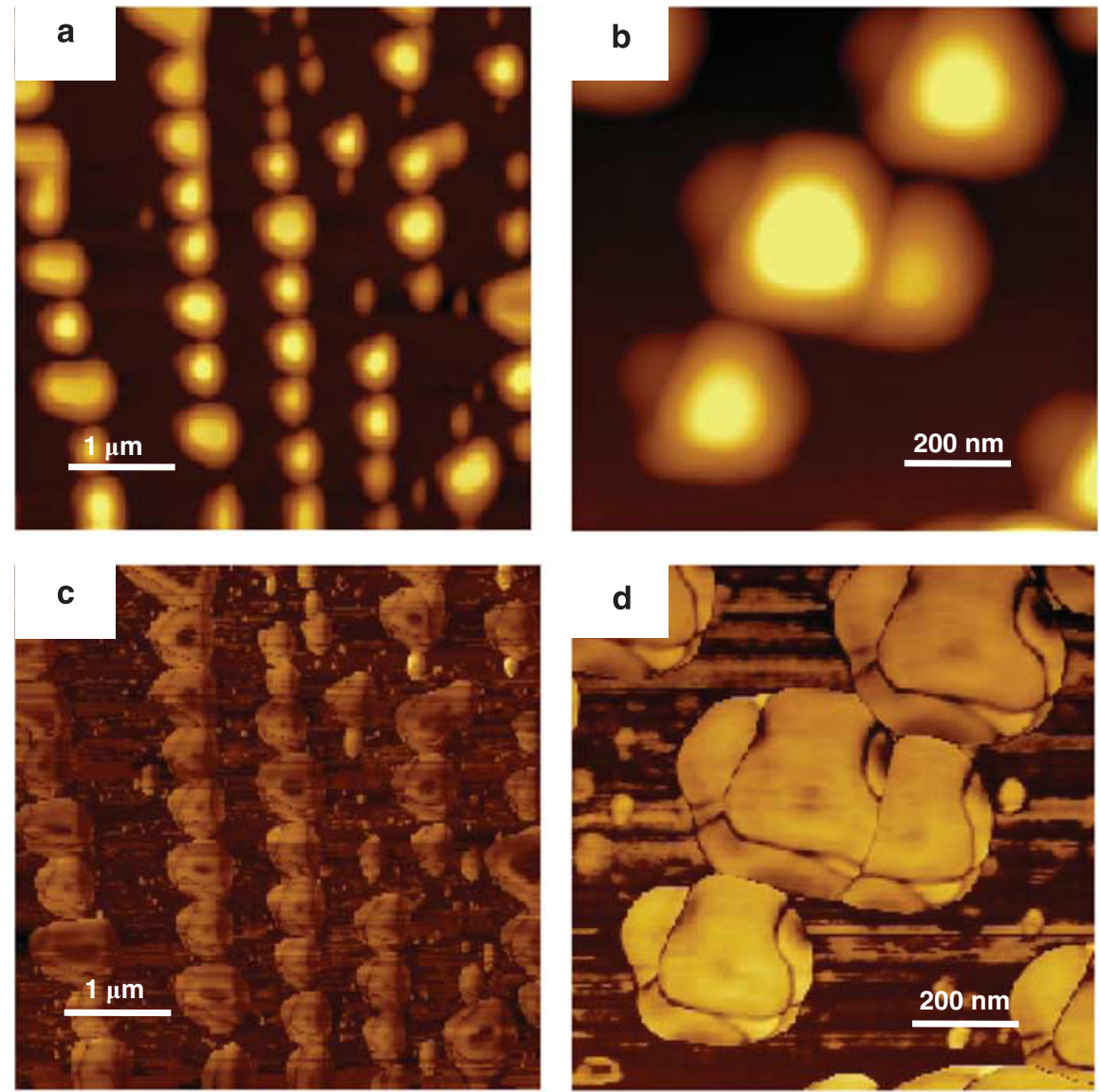

Figure 7 Scanning force microscopy (SFM) phase images of [poly 1-ethyl-3-vinylimidazolium bromide $(\mathrm{VEI}-\mathrm{Br})_{64}-b$-poly(NIPAAm) 36$]_{4}$ prepared by spin coating from aqueous solutions $\left(0.5 \mathrm{mg} \mathrm{ml}^{-1}\right)$ heated to $40^{\circ} \mathrm{C}$ onto freshly cleaved mica: (a, b) height images $(z$ range: $115 \mathrm{~nm})$, (c, d) phase images $\left(z\right.$ range: $\left.60^{\circ}\right)$ and $(b, d)$ higher magnification images. 


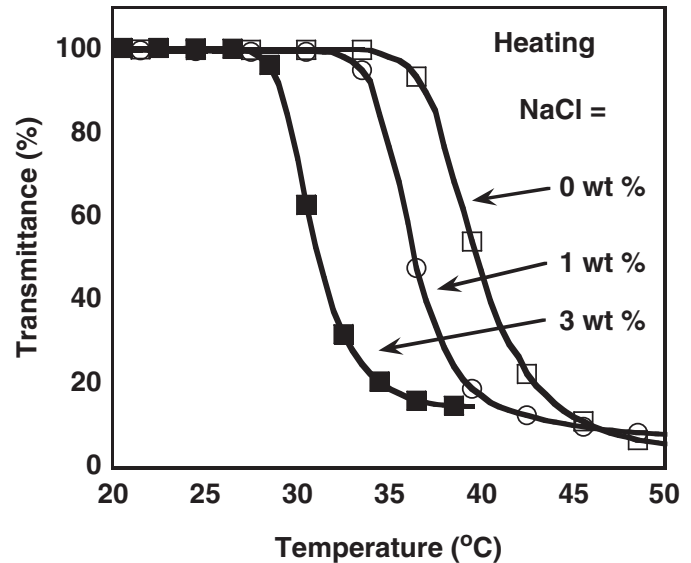

Figure 8 Temperature dependence of the transmittance at $500 \mathrm{~nm}$ in aqueous solutions (polymer conc. $=2.0 \mathrm{mg} \mathrm{ml}^{-1}$ ) of [poly 1-ethyl-3vinylimidazolium bromide $(\mathrm{VEI}-\mathrm{Br})_{64}-b$-poly(NIPAAm) $\left.{ }_{36}\right]_{4}$ in the presence and absence of $\mathrm{NaCl}$.

Scanning force microscopy was employed to visualize the assembled structure of the star block copolymer [poly(VEI-Br)- $b$ poly(NIPAAm) $]_{4}$. The sample was prepared by spin coating an aqueous solution $\left(0.5 \mathrm{mg} \mathrm{ml}^{-1}\right)$ heated to $40{ }^{\circ} \mathrm{C}$ onto freshly cleaved mica. As shown in Figure 7 , the spherical particles displayed a relatively uniform size distribution and were highly dispersed on the freshly cleaved mica. The height and phase images displayed the same shape and distribution. Spherical particles, $\sim 100 \mathrm{~nm}$ in height and $300-600 \mathrm{~nm}$ in diameter, are clearly visible in the height image that provides further evidence that aggregated structures are derived from the temperature-induced self-assembly of thermoresponsive-ionic star block copolymers.

Ionic strength and comonomer composition are important parameters for the manipulation of thermoresponsive properties, transition temperature and formation of assembled structures from ionic star block copolymers. The LCST of poly(NIPAAm) is strongly affected by the ionic strength of the aqueous solution. ${ }^{51}$ The effect of the salt concentration on the solubility of poly (ionic liquid)s in water has been observed because of the strong screening of electrostatic repulsion. ${ }^{21}$ In an aqueous solution of $[\text { poly(VEI-Br)- } b \text {-poly(NIPAAm) }]_{4}$ with $3 \mathrm{wt} \% \mathrm{NaCl}$, a clear phase transition from $100 \%$ at $25^{\circ} \mathrm{C}$ to $<20 \%$ at $35^{\circ} \mathrm{C}$ is detected (Figure 8). The transition temperature decreases with an increase in the $\mathrm{NaCl}$ concentration, indicating that these products can be regarded as dual stimuli-responsive star block copolymers.

Because various properties of ionic liquids can be tuned by adjusting the structure of the anion (for example, halide, tetrafluoroborate and hexafluorophosphate), the thermoresponsive properties and ordered structure of imidazolium-based block copolymers can be manipulated via anion exchange reactions. Here, $\left[\mathrm{poly}\left(\mathrm{VEI}-\mathrm{BF}_{4}\right)-b\right.$ poly(NIPAAm) $]_{4}$ was synthesized by reacting [poly(VEI-Br)- $b$-poly (NIPAAm) $]_{4}$ with $\mathrm{NaBF}_{4}$ at room temperature for $1 \mathrm{~h}$, according to a previously reported procedure. ${ }^{11}$ Under these conditions, a transparent aqueous solution of star block copolymer turned into a translucent dispersion, suggesting that hydrophilic poly(VEI-Br) segments in the core collapsed into hydrophobic poly $\left(\mathrm{VEI}-\mathrm{BF}_{4}\right)$ and further aggregated. Upon heating to $60^{\circ} \mathrm{C}$, the translucent dispersion changed into a white turbid dispersion with microscopic precipitation in water as a result of

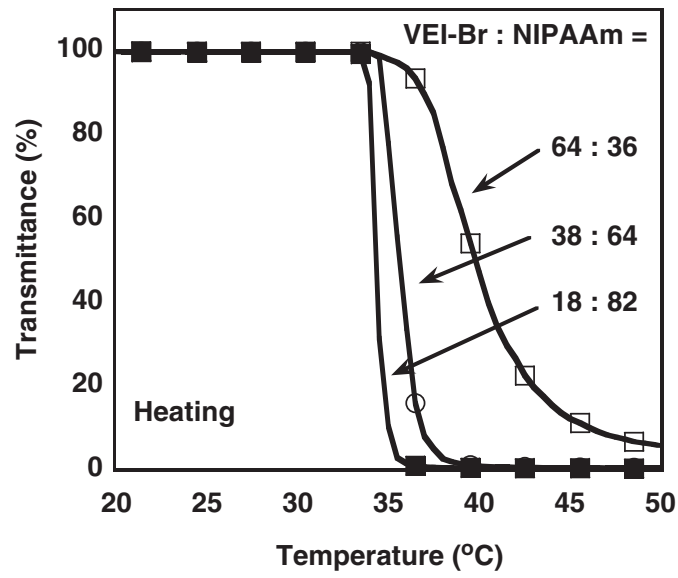

Figure 9 Temperature dependence of the transmittance at $500 \mathrm{~nm}$ in aqueous solutions (polymer conc. $=2.0 \mathrm{mg} \mathrm{ml}^{-1}$ ) of [poly 1-ethyl-3-vinylimidazolium bromide (VEI-Br)-b-poly(NIPAAm) $]_{4}$ with different comonomer compositions.

the soluble-insoluble transition of poly(NIPAAm) segments. As expected, an increase in the composition of poly $(\mathrm{VEI}-\mathrm{Br})$ segments in the block copolymer led to an increase in the solubility, which increased the transition temperature (Figure 9). These results suggest that the thermoresponsive behavior and transition temperature of ionic-thermoresponsive star block copolymers are affected by the content of the ionic segment, structure of the anion and the salt concentration.

\section{CONCLUSION}

Four-armed star block copolymers with poly(VEI-Br) and poly(NIPAAm) segments as separated inner and outer blocks and opposite sequences were prepared by RAFT polymerization, using CTA 2. These thermoresponsive-ionic star block copolymers form spherical micelles and aggregate into dehydrated clusters at temperatures above the LCST of the poly(NIPAAm) segment. The thermally induced phase separation behavior and assembled structure of the two series of star block copolymers are quite different, and depend on the sequence of each block (location of the thermoresponsive segment) along the arm of the star. The star block copolymer with block arms consisting of outer block copolymer segments of thermoresponsive poly(NIPAAm) ([poly(VEI-Br)- $b$-poly(NIPAAm) $]_{4}$ ) showed a two-step transition process. In particular, small micelles form at $\sim 33^{\circ} \mathrm{C}$ and then aggregate into dehydrated clusters. In contrast, the star block copolymer with inner thermoresponsive segments connected to the core ([poly(NIPAAm)- $b$-poly(VEI-Br) $]_{4}$ ) exhibited a rapid aggregation, and unimers dissolved in water were transformed into large micellar clusters. The present study substantially broadens the scope of thermoresponsive star block copolymers containing poly $(N$-vinylimidazolium salt)s, in which stimuli-responsive phase separation behavior and assembled structures can be fine-tuned by modifying the sequence and comonomer composition of the diblock arms, chain architecture (topology) and external stimuli such as the temperature and salt concentration.

\section{ACKNOWLEDGEMENTS}

This work was supported by the Sinsei Foundation. 
1 Lu, J., Yan, F. \& Texter, J. Advanced applications of ionic liquids in polymer science. Prog. Polym. Sci. 34, 431-448 (2009).

2 Mecerreyes, D. Polymeric ionic liquids: Broadening the properties and applications of polyelectrolytes. Prog. Polym. Sci. 36, 1629-1648 (2011).

3 Green, O., Grubjesic, S., Lee, S. \& Firestone, M. A. The design of polymeric ionic liquids for the preparation of functional materials. Polym. Rev. 49, 339-360 (2009).

4 Washiro, S., Yoshizawa, M., Nakajima, H. \& Ohno, H. Highly ion conductive flexible films composed of network polymers based on polymerizable ionic liquids. Polymer 45, 1577-1582 (2004)

5 Ding, S., Tang, H., Radosz, M. \& Shen, Y. Atom transfer radical polymerization of ionic liquid 2-(1-butylimidazolium-3-yl)ethyl methacrylate tetrafluoroborate. J. Polym. Sci. 42, 5794-5801 (2004).

6 Nakashima, T., Sakashita, M., Nonoguchi, Y. \& Kawai, T. Sensitized photopolymerization of an ionic liquid-based monomer by using CdTe nanocrystals. Macromolecules 40, 6540-6544 (2007).

7 Juger, J., Meyer, F., Vidal, F., Chevrot, C. \& Teyssié, D. Synthesis, polymerization and conducting properties of an ionic liquid-type anionic monomer. Tetrahedron Lett. 50, 128-131 (2009)

8 Tang, J., Tang, H., Sun, W., Radosz, M. \& Shen, Y. Poly(ionic liquid)s as new materials for CO2 absorption. J. Polym. Sci. 43, 5477-5489 (2005).

9 Tang, H., Tang, J., Ding, S., Radosz, M. \& Shen, Y. Atom transfer radical polymerization of styrenic ionic liquid monomers and carbon dioxide absorption of the polymerized ionic liquids. J. Polym. Sci. 43, 1432-1443 (2005).

10 Leddet, C., Fischer, A., Brembilla, A. \& Lochon, P. Influence of the alkyl-chain size on the amphiphilic behaviour of poly(3-alkyl-1-vinylimidazolium) bromide in aqueous medium. Polym. Bull. 46, 75-82 (2001).

11 Marcilla, R., Blazquez, J. A., Rodriguez, J., Pomposo, J. A. \& Mecerreyes, D. Tuning the solubility of polymerized ionic liquids by simple anion-exchange reactions. J. Polym. Sci. 42, 208-212 (2004).

12 Amajjahe, S. \& Ritter, H. Microwave-sensitive foamable poly(ionic liquids) bearing tertbutyl ester groups: influence of counterions on the ester pyrolysis. Macromol.Rapid Commun. 30, 94-98 (2009).

13 Marcilla, R., Blazquez, J. A., Fernandez, R., Grande, R., Pomposo, J. A. \& Mecerreyes, D. Synthesis of novel polycations using the chemistry of ionic liquids. Macromol. Chem. Phys. 206, 299-304 (2005).

14 Green, M. D., Allen, M. H., Dennis, J. M., Cruz, D. S., Gao, R., Winey, K. I. \& Long, T. E. Tailoring macromolecular architecture with imidazole functionality: a perspective fo controlled polymerization processes. Eur. Polym. J. 47, 486-496 (2011).

15 Yua, J. \& Antonietti, M. Poly(ionic liquid) latexes prepared by dispersion polymerization of ionic liquid monomers. Macromolecules 44, 744-750 (2011).

16 Stancik, C. M., Lavoie, A. R., Schütz, J., Achurra, P. A., Lindner, P., Gast, A. P. \& Waymouth, R. M. Micelles of imidazolium-functionalized polystyrene diblock copolymers investigated with neutron and light scattering. Langmuir 20, 596-605 (2004).

17 Stancik, C. M., Lavoie, A. R., Achurra, P. A., Waymouth, R. M. \& Gast, A. P. A. Neutron scattering study of the structure and water partitioning of selectively deuterated copolymer micelles. Langmuir 20, 8975-8987 (2004).

18 Vijayakrishna, K., Jewrajka, S. K., Ruiz, A., Marcilla, R., Pomposo, J. A., Mecerreyes D., Taton, D. \& Gnanou, Y. Synthesis by RAFT and ionic responsiveness of double hydrophilic block copolymers based on ionic liquid monomer units. Macromolecules 41, 6299-6308 (2008).

19 Yang, J., Sun, W., Lin, W. \& Shen, Z. Synthesis and magnetic properties of comb-like copolymeric complexes based on thiazole ring and ionic liquid. J. Polym. Sci. 46, 5123-5132 (2008)

20 Mori, H., Yahagi, M. \& Endo, T. RAFT Polymerization of N-vinylimidazolium salts and synthesis of thermoresponsive ionic liquid block copolymers. Macromolecules 42 , 8082-8092 (2009)

21 Yuan, J., Schlaad, H., Giordano, C. \& Antonietti, M. Double hydrophilic diblock copolymers containing a poly(ionic liquid) segment: Controlled synthesis, solution property, and application as carbon precursor. Eur. Polym. J. 47, 772-781 (2011).

22 Hirao, A., Hayashi, M., Loykulant, S., Sugiyama, K., Ryu, S. W., Haraguchi, N., Matsuo, A. \& Higashihara, T. Precise syntheses of chain-multi-functionalized polymers, star-branched polymers, star-linear block polymers, densely branched polymers, and dendritic branched polymers based on iterative approach using functionalized 1,1 diphenylethylene derivatives. Prog. Polym. Sci. 30, 111-182 (2005).

23 Riess, G. Micellization of block copolymers. Progress in Polymer Science 28, 1107 1170 (2003).

24 Mori, H. \& Müller, A. H. E. New polymeric architectures with (meth)acrylic acid segments. Prog. Polym. Sci. 28, 1403-1439 (2003)

25 Hadjichristidis, N., latrou, H., Pitsikalis, M., Pispas, S. \& Avgeropoulos, A. Linear and non-linear triblock terpolymers. Synthesis, self-assembly in selective solvents and in bulk. Progress in Polymer Science 30, 725-782 (2005).

26 Bernaerts, K. V. \& Du Prez, F. E. Dual/heterofunctional initiators for the combination of mechanistically distinct polymerization techniques. Progress in Polymer Science 31, 671-722 (2006)

27 Yagci, Y. \& Tasdelen, M. A. Mechanistic transformations involving living and controlled/ living polymerization methods. Progress in Polymer Science 31, 1133-1170 (2006).
28 Taton, D., Gnanou, Y., Matmour, R., Angot, S., Hou, S., Francis, R., Lepoittevin, B. Moinard, D. \& Babin, J. Controlled polymerizations as tools for the design of star-like and dendrimer-like polymers. Polymer International 55, 1138-1145 (2006).

29 Zhang, W., Zhang, W., Cheng, Z., Zhu, J., Zhang, Z., Chen, G. \& Zhu, X. Synthesis and aggregation behaviors of nonlinear multiresponsive, multihydrophilic block copolymers. Macromolecules 44, 3366-3373 (2011).

$30 \mathrm{Li}$, C., Lavigueur, C. \& Zhu, X. X. Aggregation and thermoresponsive properties of new star block copolymers with a cholic acid core. Langmuir 27, 11174-11179 (2011).

31 Zhu, W., Nese, A. \& Matyjaszewski, K. Thermoresponsive star triblock copolymers by combination of ROP and ATRP: from micelles to hydrogels. Journal of Polymer Science, Part A: Polymer Chemistry 49, 1942-1952 (2011).

32 Luo, S., Ling, C., Hu, X., Liu, X., Chen, S., Han, M. \& Xia, J. Thermoresponsive unimolecular micelles with a hydrophobic dendritic core and a double hydrophilic block copolymer. Journal of Colloid and Interface Science 353, 76-82 (2011).

33 Park, J., Moon, M., Seo, M., Choi, H. \& Kim, S. Y. Well-defined star-shaped rod-coil diblock copolymers as a new class of unimolecular micelles: Encapsulation of guests and thermoresponsive phase transition. Macromolecules 43, 8304-8313 (2010).

34 Zhou, Y.-M., Ishikawa, A., Okahashi, R., Uchida, K., Nemoto, Y., Nakayama, M. \& Nakayama, Y. Deposition transfection technology using a DNA complex with a thermoresponsive cationic star polymer. Journal of Controlled Release 123, 239 246 (2007).

35 Cao, Z., Liu, W., Ye, G., Zhou, X., Lin, X., Gao, P. \& Yao, K. N-isopropylacrylamide/2hydroxyethyl methacrylate star diblock copolymers: Synthesis and thermoresponsive behavior. Macromolecular Chemistry and Physics 207, 2329-2335 (2006).

36 Mayadunne, R. T. A., Jeffery, J., Moad, G. \& Rizzardo, E. Living free radical polymerization with reversible addition-fragmentation chain transfer (RAFT polymerization): approaches to star polymers. Macromolecules 36, 1505-1513 (2003).

37 Robin, S., Guerret, O., Couturier, J.-L. \& Gnanou, Y. Poly(vinyl ester) star polymers via xanthate-mediated living radical polymerization: from poly(vinyl alcohol) to glycopolymer stars. Macromolecules 38, 5475-5484 (2005).

38 Barner, L., Davis, T. P., Stenzel, M. H. \& Barner-Kowollik, C. Complex macromolecular architectures by reversible addition fragmentation chain transfer chemistry: theory and practice. Macromolecular Rapid Communications 28, 539-559 (2007).

39 Dureault, A., Taton, D., Destarac, M., Leising, F. \& Gnanou, Y. Synthesis of multifunctional dithioesters using tetraphosphorus decasulfide and their behavior as RAFT agents. Macromolecules 37, 5513-5519 (2004).

40 Boschmann, D. \& Vana, P. Z-RAFT star polymerizations of acrylates: Star coupling via intermolecular chain transfer to polymer. Macromolecules 40, 2683-2693 (2007).

41 Chaffey-Millar, H., Stenzel, M. H., Davis, T. P., Coote, M. L. \& Barner-Kowollik, C. Design criteria for star polymer formation processes via living free radical polymerization. Macromolecules 39, 6406-6419 (2006).

42 Mori, H., Ookuma, H. \& Endo, T. Synthesis of star polymers based on xanthatemediated controlled radical polymerization of N-Vinylcarbazole. Macromol. Symp. 249 250 406-411 (2007)

43 Chiefari, J., Mayadunne, R. T. A., Moard, C. L., Rizzardo, E., Postma, A., Skidmore, M. A \& Thang, S. H. Thiocarbonylthio compounds $(S=C(Z) S-R)$ in free radical polymerization with reversible addition-fragmentation chain transfer (RAFT polymerization). Effect of the activating group Z. Macromolecules 36, 2273-2283 (2003)

44 Mayadunne, R. T. A., Rizzardo, E., Chiefari, J., Chong, Y. K., Moad, G. \& Thang, S. H. Living radical polymerization with reversible addition-fragmentation chain transfer (RAFT Polymerization) using dithiocarbamates as chain transfer agents. Macromole cules 32, 6977-6980 (1999).

45 Schilli, C., Lanzendörfer, M. G. \& Müller, A. H. E. Benzyl and cumyl dithiocarbamates as chain transfer agents in the RAFT polymerization of $\mathrm{N}$-isopropylacrylamide. In situ FT-NIR and MALDI-TOF MS investigation. Macromolecules 35, 6819-6827 (2002).

46 Maki, Y., Mori, H. \& Endo, T. Controlled RAFT polymerization of $N$-vinylphthalimide and its hydrazinolysis to poly(vinyl amine). Macromolecular Chemistry and Physics 208, 2589-2599 (2007).

47 Maki, Y., Mori, H. \& Endo, T. Synthesis of well-defined alternating copolymers by RAFT copolymerization of $N$-vinylnaphthalimide. Macromolecules 41, 8397-8404 (2008).

48 Moad, G., Li, J. \& Chen, L. Living free radical polymerization with reversible additionfragmentation chain transfer (the life of RAFT). Polymer International 49, 993-1001 (2000).

49 Stenzel, M. H., Davis, T. P. \& Barner-Kowollik, C. Poly(vinyl alcohol) star polymers prepared via MADIX/RAFT polymerization 1546-1547 (Chemical Communications, Cambridge, 2004).

50 Nguyen, U. T. L., Eagles, K., Davis, T. P., Barner-Kowollik, C. \& Stenzel, M. H. Investigation of the influence of the architectures of poly(vinyl pyrrolidone) polymers made via the reversible addition-fragmentation chain transfer/macromolecular design via the interchange of xanthates mechanism on the stabilization of suspension polymerizations. Journal of Polymer Science: Part A: Polymer Chemistry 44, 43724383 (2006)

51 Bokias, G., Staikos, G. \& Iliopoulos, I. Solution properties and phase behaviour of copolymers of acrylic acid with $\mathrm{N}$-isopropylacrylamide: the importance of the intrachain hydrogen bonding. Polymer 41, 7399-7405 (2000). 